\title{
Ex ante appraisal of agricultural research and extension
}

\section{A choice experiment on climbing beans in Burundi}

\author{
Isabel Lambrecht, Liesbet Vranken, Roel Merckx, \\ Bernard Vanlauwe and Miet Maertens
}

\begin{abstract}
Research on agricultural technology adoption generally occurs ex post, after the introduction of a technology. In this paper, the authors use a choice experiment to reveal farmers' preferences for new agricultural technologies ex ante, before new technologies are developed and introduced. The authors implement a choice experiment among 200 farmers in Burundi and use mixed logit models to analyse preferences for specific traits of improved climbing bean varieties. It was found that farmers had a strong preference for climbing bean varieties that resulted in higher yields and improved soil fertility, while the maturation period and the responsiveness to fertilizer were less important. Seed price was found to matter only for the most food-insecure farmers. These choice experimental results can inform agricultural research and extension programmes ex ante to take into account farmers' preferences and accelerate the adoption of new technologies.
\end{abstract}

Keywords: agricultural research and extension; technology adoption; choice experiment; climbing beans; Sub-Saharan Africa

Isabel Lambrecht is with the Development Strategy and Governance Division, International Food Policy Research Institute, CSIR Campus, Airport Residential Area, PMB CT 112 Cantonments, Accra, Ghana, and the Bioeconomics Division, KU Leuven, Celestijnenlaan 200E - bus 2411, 3001 Heverlee, Belgium. E-mail: i.lambrecht@cgiar.org. Liesbet Vranken is also with the Bioeconomics Division, KU Leuven. Roel Merckx is with the Division of Soil and Water Management, KU Leuven, Kasteelpark Arenberg 20, 3001 Heverlee, Belgium. Bernard Vanlauwe is with IITA, c/o ICIPE, PO Box 30772-00100, Nairobi, Kenya. E-mail:eb.vanlauwe@cgiar.org. Miet Maertens (corresponding author) is with the Bioeconomics Division, KU Leuven. E-mail: miet.maertens@kuleuven.be.

Improved technologies are crucial for achieving agricultural production and productivity growth, and hence for alleviating poverty and food insecurity (Irz et al, 2001). Agricultural research and extension have an important role to play, especially in regions lagging behind in the use of modern technologies. However, research on agricultural technology adoption generally occurs ex post, after the introduction of a technology. In this paper, we use a choice experiment to reveal farmers' preferences for new agricultural technologies ex ante, before new tech- nologies are developed and introduced.

Understanding which technology traits appeal to which farmers can contribute to improved technology design, more efficient dissemination strategies and increased adoption rates. We specifically focus on improved climbing bean varieties in Burundi, one of the poorest and most densely populated countries in the world, where the majority of the population depends on agriculture (Beekman and Bulte, 2012). Beans are an important part of the staple diet, and climbing beans have 
a high yield potential and a high symbiotic nitrogen fixation capacity (Checa et al, 2006; Graham and Rosas, 1977). Introducing improved climbing bean varieties could be a promising avenue to improve soil fertility, increase rural incomes and alleviate poverty and food insecurity in Burundi (Pypers et al, 2011).

\section{Materials and methods}

\section{Choice experiment design}

A discrete choice experiment (CE) is a method of revealing people's preferences. The method is common in marketing research to reveal consumer preferences for product characteristics and in environmental valuation (for example, Rousseau and Vranken, 2013; Hoyos, 2010). It is gaining ground in agricultural economics to assess farmers' preferences for crop, livestock and technology traits (Bennett and Birol, 2010). In a CE, respondents are presented with alternative varieties of goods or services, in this case an agricultural technology, differentiated by their attributes and attribute levels, and asked to select their most preferred variety. This information allows the modelling of farmers' preferences for hypothetical technology characteristics, thereby revealing which technologies are more likely to be adopted by farmers.

\section{Attributes and attribute levels}

To identify the attributes, we interviewed climbing bean experts and conducted gender-separated group discussions with farmers in our research area. This resulted in the identification of five relevant attributes of improved climbing bean varieties (Table 1): (i) maturation period, (ii) increase in bean yield with mineral fertilizer application, (iii) increase in bean yield without mineral fertilizer application, (iv) increased soil fertility for the following season, and (v) seed price. Many other characteristics of climbing bean varieties, such as seed colour, palatability or cooking time, were also mentioned as playing a role in farmers' seed valuation during the group discussions. However, to keep the CE comprehensive, we limited the number of attributes to five. For each attribute we defined three attribute levels. A larger number of attribute levels would have led to more detailed insights in preferences, but would have necessitated a higher number of choice sets (Hensher et al, 2005).

The first attribute (maturation period) is expressed as the number of days from planting to crop maturity (Table 1). Increasing the amount of biomass in the form of crop residues can have a beneficial impact on soil fertility, but may entail a longer maturation period. Together with climbing bean experts, we determined the range in which climbing bean maturation was biophysically feasible in our research area. During focus group discussions, respondents agreed that varieties with a maturation period over 125 days would never be accepted by farmers. In the period between investment and harvest, poor households often face cash constraints, resulting in reduced consumption or hunger. A longer maturation period may increase the length of this 'hungry season' and jeopardize timely sowing for the next season. We therefore expect farmers to dislike a longer maturation period. However, farmers who mix different varieties with different maturation periods in the field can smooth out patterns of consumption and sales, and may thus have less strong preferences for a shorter maturation period.

The second and third attributes are climbing bean yields without and with mineral fertilizer use respectively (Table 1). The group discussions revealed that farmers have difficulties in accurately estimating crop yields. It was agreed that the best strategy would be to express the yield benefit as an additional output per $\mathrm{kg}$ of seeds sown in comparison with farmers' current average yield. The yield response of improved climbing bean varieties probably improves with mineral fertilizer application (Vanlauwe et al, 2010). We therefore include the yield increase with and without mineral fertilizer as two separate attributes. The exact levels of the yield increases were based on the characteristics of the improved climbing bean varieties that were candidates for dissemination in the research area. Whether farmers value yield in-

Table 1. Attributes and attribute levels used in the choice experiment.

\begin{tabular}{|c|c|c|}
\hline Attribute & Definition & Attribute levels \\
\hline Maturation period & The number of days from bean planting to harvest maturity & $\begin{array}{l}95 \text { days } \\
110 \text { days (SQ) } \\
125 \text { days }\end{array}$ \\
\hline Productivity without mineral fertilizer & $\begin{array}{l}\text { Average yield increase for each } 1 \mathrm{~kg} \text { of climbing beans sown without the } \\
\text { addition of mineral fertilizer }\end{array}$ & $\begin{array}{l}0 \mathrm{~kg}(\mathrm{SQ}) \\
2.5 \mathrm{~kg} \\
5 \mathrm{~kg}\end{array}$ \\
\hline Productivity with mineral fertilizer & $\begin{array}{l}\text { Average yield increase for each } 1 \mathrm{~kg} \text { of climbing beans sown if mineral } \\
\text { fertilizer is applied }\end{array}$ & $\begin{array}{l}0 \mathrm{~kg}(\mathrm{SQ}) \\
10 \mathrm{~kg} \\
20 \mathrm{~kg}\end{array}$ \\
\hline Soil fertility improvement & $\begin{array}{l}\text { Improvement in soil fertility, expressed in yield increase of } 1 \mathrm{~kg} \text { sown of the } \\
\text { rotating maize crop }\end{array}$ & $\begin{array}{l}0 \mathrm{~kg}(\mathrm{SQ}) \\
7.5 \mathrm{~kg} \\
15 \mathrm{~kg}\end{array}$ \\
\hline Seed price & The amount of money the farmer needs to pay for $1 \mathrm{~kg}$ of seeds & $\begin{array}{l}\text { 1,000 FBu (SQ) } \\
\text { 1,250 FBu } \\
1,500 \mathrm{FBu}\end{array}$ \\
\hline
\end{tabular}

Note: $\mathrm{FBu}=$ Burundian francs; FBu 1,250 = US\$1 at the time of the experiment (September 2011); (SQ) level of the status quo or opt-out option. 
Appraisal of agricultural research and extension

creases with or without mineral fertilizer probably depends on whether or not they apply mineral fertilizer on their fields. We expect that the yield of climbing beans with mineral fertilizer application matters most to farmers who have already adopted mineral fertilizer.

The fourth attribute relates to soil fertility improvement (Table 1). As suggested by respondents during focus group discussions, we define this as a yield increase for the subsequent maize crop. Most farmers in the area are rotating beans with maize, such that nutrient replenishment associated with improved climbing varieties would materialize in higher maize yields the following season. One study on climbing bean-maize rotation in South Kivu (Lunze and Ngongo, 2011) found a positive effect of climbing bean cultivation on the yield of the subsequent maize crop. They showed yield increases of 15 to $46 \%$ maize grain in rotation with climbing bean. The exact attribute levels have been chosen based on the advice of the programme agronomists and results of climbing bean field experiments in the area. We expect that farmers will prefer soil fertility improvements or future maize yield increases, but that this effect will be substantially lower than for more immediate increases in bean yields. There may also be a large trade-off between current investments and future returns, even if the future is a relatively short time span of two agricultural seasons. We also expect the relative difference between these two effects to be higher for poorer households.

The fifth attribute is the seed price, expressed as the price paid for one $\mathrm{kg}$ of seeds (Table 1). The price levels were chosen based on the market price at the time of the survey, and the maximum and minimum price that were found to be realistic by focus group respondents. We expect that farmers will prefer lower production costs, and therefore a lower seed price. Poorer households are more cash-constrained, and we expect that the poorest households will have the strongest preferences for varieties with a lower seed price, and hence that the effect of the seed price attribute will increase (or become less negative) with farmers' welfare level. In addition, we expect that farmers with access to agricultural input credit will have less pronounced preferences for a lower seed price compared to farmers without access to credit.

\section{Choice cards}

We developed choice cards consisting of two generic alternatives and a status quo or opt-out option (Figure 1). This last option was added to allow respondents not to adopt improved climbing bean varieties (Hensher et al, 2005). Given that we selected five attributes with three levels, the number of possible choices is high. In a fullfactorial design, all the main effects, all two-way interactions and all higher-order interactions are estimable and uncorrelated. The problem is that respondents need to consider all possible combinations, which is tedious to implement in practice. We therefore used a fractional factorial design, a subsample of the full factorial design, to select choices and combine them in choice cards. With this procedure we arrived at a total of 27 different choice cards, separated into three blocks or subsets of nine choice cards. The choice sets were carefully checked to rule out dominant choices in which one alternative was strictly better than another.

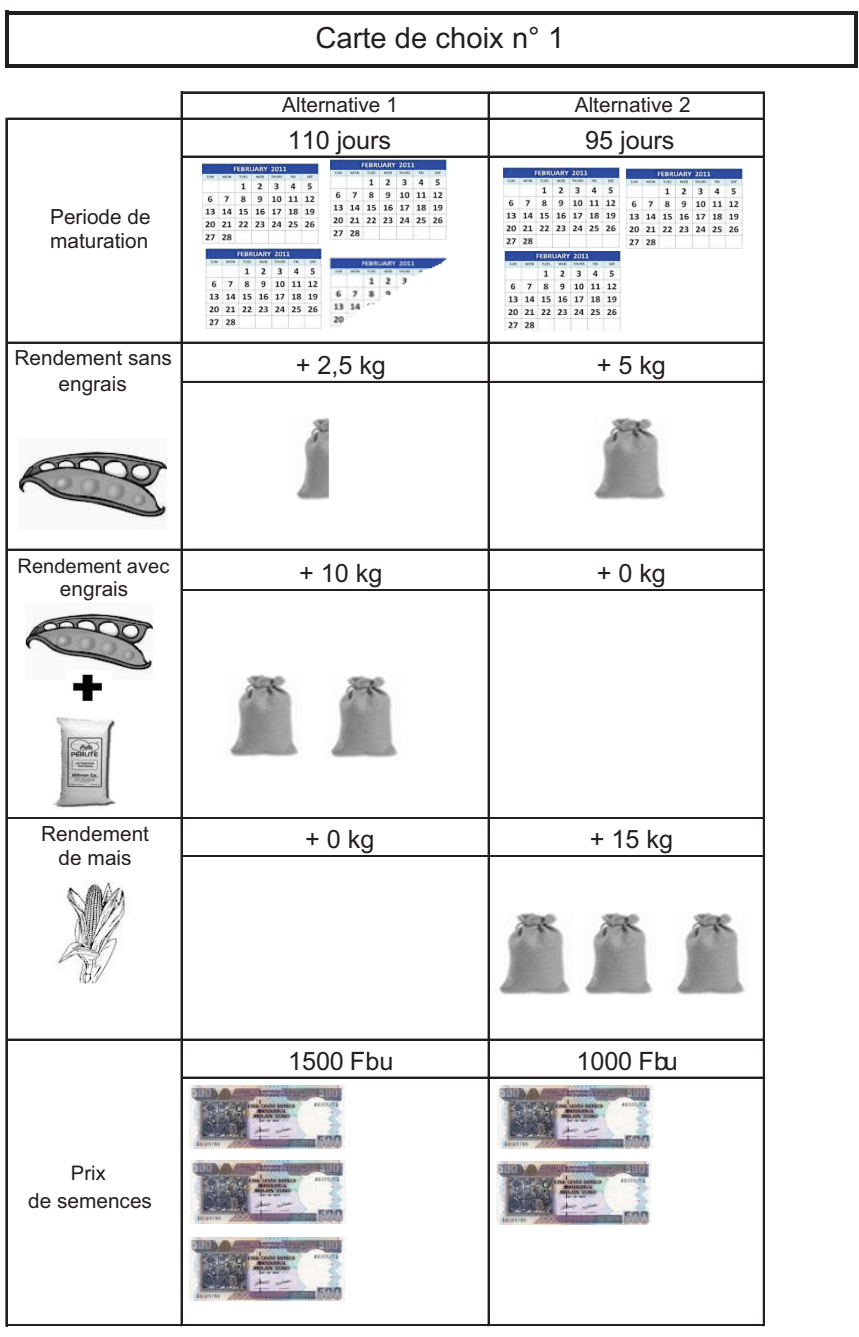

Figure 1. Example of a choice card as shown to the respondents during the interview.

\section{Study area and data collection}

Our study area covers two communes, Mutaho and Makebuko, in Gitega province, Burundi. Since 2006, the Consortium for Improving Agriculture-based Livelihoods in Central Africa (CIALCA) has been introducing integrated soil fertility management (ISFM) technologies, including improved climbing bean varieties, in several collines ${ }^{1}$ in these communes. We focused on those collines that were not yet part of the programme, but where activities for outscaling were planned. In a three-stage sampling design we randomly selected four collines in each commune, one or two sous-collines in each selected colline, and a total of 200 households in these souscollines. Because climbing beans are almost exclusively grown by women in our case study area, we focused on female respondents.

The CE was carried out between September and October 2011 and was accompanied by a small survey. The respondents were randomly assigned to one of the three choice blocks, each comprising nine choice cards. The choice task was comprehensively introduced to the respondents to make sure the task of hypothetically buying improved climbing bean varieties, or not (opt- 
out), was properly understood. Each respondent was then asked to choose among two improved varieties and the opt-out option for each of the nine choice cards. A pilot test before the actual CE confirmed the respondents' understanding of the choice task.

\section{Econometric approach}

We use mixed logit (MXL) models (Hensher and Greene, 2003) to analyse the CE data and reveal farmers' preferences for specific traits of improved climbing bean varieties and how these preferences vary with farm and farmer characteristics. In a first MXL model, we used the full sample and included three interaction terms to reveal preference heterogeneity across farmers: (i) interaction between seed price and a dummy variable indicating whether the household had received agricultural input credit during the past year, (ii) interaction between yield with mineral fertilizer and a dummy variable indicating whether the household had applied mineral fertilizer on climbing beans during the past year, and (iii) interaction between maturation period and a dummy variable indicating whether or not farmers had sown different climbing bean varieties. Based on a Lagrange Multiplier test, we treated all the parameters in the MXL model as random (McFadden and Train, 2000). We used 500 Halton draws, ${ }^{2}$ which provided sufficient balance between stability of the estimates and estimation time. To account for multiple choices by each respondent, the data are clustered at respondent level (Hensher and Greene, 2003).

In a second set of MXL models, we split the sample into different food security categories and estimated the same MXL model for each subsample separately. This is a simple method that allows us to interpret preference heterogeneity easily. We distinguished three food insecu- rity categories based on a set of nine standardized questions related to the frequency of experiencing specific household food insecurity situations and following the guidelines of the FANTA project (Coates et al, 2007): (i) least food-insecure, (ii) moderately food-insecure, and (iii) severely food-insecure.

\section{Results and discussion}

\section{Household and respondent characteristics}

One in 10 households in our sample was female-headed (Table 2). These households are managed by a female farmer who has been widowed, divorced or abandoned by her male spouse. Households generally consist of two to three adults and two to three children. They own on average four fields and less than one livestock unit (which equals one cow). Education levels are low, with on average 2.9 years of schooling. Only $9 \%$ of households in our sample are food-secure, and $40 \%$ are severely foodinsecure. Compared to the moderately and severely food-insecure, the least food-insecure households have more human and physical capital, with higher levels of education and more livestock, fields and other assets (Table 2). In addition, they have a higher probability of being a member of an association. Almost all of these households live in Makebuko. Similarly, compared to the severely food-insecure, moderately food-insecure households have higher levels of education and more land, livestock and other assets. They are more likely to live in Makebuko. Severely food-insecure households are more likely to have received agricultural input credit.

We found that nearly all households (96\%) had experience of using mineral fertilizer on their own farm

Table 2. Household and respondent characteristics for three food insecurity categories.

\begin{tabular}{|c|c|c|c|c|c|c|}
\hline & \multirow{2}{*}{$\begin{array}{c}\text { All } \\
\text { Mean }(S D)\end{array}$} & \multirow{2}{*}{$\begin{array}{l}\text { Least food- } \\
\text { insecure } \mathbf{I}^{\mathbf{a}} \\
\text { Mean (SD) }\end{array}$} & \multicolumn{2}{|c|}{$\begin{array}{l}\text { Moderately food- } \\
\text { insecure } \text { II }^{\mathrm{a}}\end{array}$} & \multicolumn{2}{|c|}{$\begin{array}{l}\text { Severely food- } \\
\text { insecure III }\end{array}$} \\
\hline & & & Mean (SD) & $b$ & Mean (SD) & $c$ \\
\hline Female household head & 0.11 & 0.13 & 0.11 & & 0.09 & \\
\hline \multirow[t]{2}{*}{ Education of respondent (years) } & 2.91 & 4.53 & 2.98 & *** & 2.23 & ** \\
\hline & $(2.70)$ & $(2.32)$ & $(2.67)$ & & $(2.62)$ & \\
\hline \multirow[t]{2}{*}{ Adults } & 2.77 & 3.23 & 2.73 & ** & 2.63 & \\
\hline & $(1.27)$ & $(1.41)$ & $(1.23)$ & & $(1.24)$ & \\
\hline \multirow[t]{2}{*}{ Children } & 2.61 & 2.63 & 2.79 & & 2.40 & * \\
\hline & $(1.63)$ & $(1.67)$ & $(1.71)$ & & $(1.51)$ & \\
\hline \multirow[t]{2}{*}{ Tropical livestock units ${ }^{\mathrm{d}}$} & 0.87 & 1.47 & 0.85 & $* * *$ & 0.66 & ** \\
\hline & $(0.83)$ & $(1.15)$ & $(0.69)$ & & $(0.73)$ & \\
\hline \multirow[t]{2}{*}{ Number of fields owned } & 4.27 & 5.70 & 4.45 & ** & 3.54 & ** \\
\hline & $(2.77)$ & $(3.45)$ & $(2.98)$ & & $(1.92)$ & \\
\hline \multirow[t]{2}{*}{ Asset index } & 2.36 & 3.97 & 2.36 & *** & 1.74 & *** \\
\hline & (1.51) & (1.99) & (1.15) & & (1.19) & \\
\hline Received agricultural input credit last year & 0.28 & 0.23 & 0.22 & & 0.35 & $* *$ \\
\hline Association member & 0.54 & 0.90 & 0.49 & *** & 0.46 & \\
\hline Commune (1 = Makebuko) & 0.48 & 0.97 & 0.50 & *** & 0.28 & *** \\
\hline$N$ & 200 & 30 & 90 & & 80 & \\
\hline
\end{tabular}

Notes: aHousehold food insecurity categories determined according to FANTA method (Coates et al, 2007). Group I consists of food-

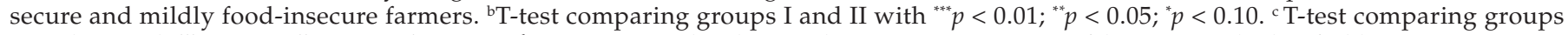
II and III with ${ }^{* * *} p<0.01 ;{ }^{* *} p<0.05 ;{ }^{*} p<0.10$. ${ }^{\mathrm{d}}$ One cow equals 1 livestock unit, pig is 0.40 , goat/sheep 0.20 , chicken/rabbit 0.05 , guinea pig 0.005. ${ }^{\text {e }}$ The asset index is the first term of a principal component analysis on ownership of household durables (excluding productive assets) (Filmer and Pritchett, 2001). 
Table 3. Agronomic characteristics for three food insecurity categories.

\begin{tabular}{|c|c|c|c|c|c|c|}
\hline & \multirow{2}{*}{$\begin{array}{c}\text { All } \\
\text { Mean }\end{array}$} & \multirow{2}{*}{$\begin{array}{l}\text { Least food- } \\
\text { insecure } \mathrm{I}^{\mathrm{a}} \\
\text { Mean }\end{array}$} & \multicolumn{2}{|c|}{$\begin{array}{l}\text { Moderately food- } \\
\text { insecure } \text { II }^{\mathrm{a}}\end{array}$} & \multicolumn{2}{|c|}{$\begin{array}{l}\text { Severely food- } \\
\text { insecure III }\end{array}$} \\
\hline & & & Mean & $b$ & Mean & $c$ \\
\hline Ever tried mineral fertilizer & 0.96 & 0.97 & 0.99 & & 0.93 & ** \\
\hline Applied mineral fertilizer to climbing beans last year & 0.82 & 0.77 & 0.82 & & 0.83 & \\
\hline Ever tried improved varieties & 0.28 & 0.40 & 0.28 & & 0.23 & \\
\hline Used improved varieties last year & 0.20 & 0.40 & 0.18 & $* * *$ & 0.15 & \\
\hline Climbing bean top 3 important subsistence crop & 0.82 & 0.50 & 0.86 & $* * *$ & 0.89 & \\
\hline Maize top 3 important subsistence crop & 0.56 & 0.77 & 0.50 & $* * *$ & 0.55 & \\
\hline Mix climbing bean varieties & 0.23 & 0.23 & 0.17 & & 0.30 & ** \\
\hline Used improved climbing bean variety last year & 0.06 & 0.00 & 0.06 & * & 0.08 & \\
\hline Sold climbing beans last year & 0.48 & 0.47 & 0.47 & & 0.44 & \\
\hline$N$ & 200 & 30 & 90 & & 80 & \\
\hline
\end{tabular}

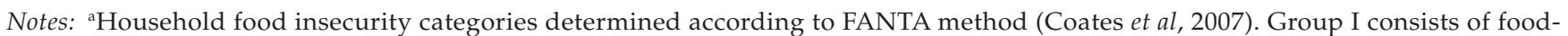
secure and mildly food-insecure farmers. ${ }^{b}$ T-test comparing groups I and II with ${ }^{* * *} p<0.01 ;{ }^{* *} p<0.05 ;{ }^{*} p<0.10$. ${ }^{c}$ T-test comparing groups II and III with ${ }^{* * *} p<0.01 ; * * 0.05 ; " p<0.10$.

(Table 3). Only $28 \%$ had ever used improved varieties of any type of crop and only $6 \%$ had used improved climbing bean varieties during the last year. The use of improved varieties is significantly higher for the least food-insecure, compared with the moderately and severely food-insecure households. Climbing beans are one of the three main subsistence crops for $82 \%$ of households, and significantly more important for the moderately $(86 \%)$ and severely food-insecure (89\%). Maize also belongs to the three main subsistence crops for $56 \%$ of all households, but it is more important for the least food-insecure $(77 \%)$. Only a quarter of the households mix climbing bean varieties in the field. About half of the households had sold a part of their climbing bean harvest. The majority $(82 \%)$ had applied mineral fertilizer on their climbing beans.

\section{MXL model results}

Using a likelihood ratio test (Greene, 2008), we found that the MXL model with interaction terms significantly improved model fit over conditional logit models or an MXL model without interaction effects (results not shown). This indicates that it is important to control for both observed and unobserved heterogeneity in the analysis. Results of the MXL model for the full sample, plus the results of the separate MXL estimations for the three food insecurity categories, are shown in Table 4 . All models confirmed that respondents preferred higher yields. The results showed that respondents in general disliked opting out (in only four of 1,800 options did respondents choose the opt-out) and had statistically significant positive preferences for increased climbing bean yields with and without mineral fertilizer application, and for increased soil fertility or increased yields in subsequent maize production. As expected, respondents who usually applied mineral fertilizer on climbing beans had a stronger preference for increased yields with mineral fertilizer.

We also found that the seed price was appreciated in different ways by different respondents. First, we distinguish between farmers with and without access to agricultural input credit. We find a significant negative effect of a higher seed price for farmers without access to agricultural input credit, but no statistically significant effect for farmers with access to agricultural input credit. This indicates that respondents without access to agricultural input credit prefer a lower seed price, while respondents with access to agricultural input credit have no statistically significant preference for the seed price. Preferences also differ among the food security categories. On average, the least and moderately food-insecure respondents had no statistically significant preferences for the seed price, while severely food-insecure respondents preferred a lower seed price. This is in line with expectations that the effect of this attribute would be most negative among the poorest households.

The effect of the maturation period is not statistically significant in the full sample, which is contrary to the expectation that a longer maturation period decreases the likelihood of adopting new varieties. This is rather counterintuitive, as a longer maturation period was expected to be disliked by farmers. However, we found weak evidence that respondents who cultivated a single bean variety did prefer a shorter maturation period (significance level $p=0.142$ ). For the least food-insecure, we found a significant negative effect of the maturation period for households that used a single bean variety, but a positive effect of the interaction term between maturation period and cultivating a mix of bean varieties. Respondents who were planting a single variety preferred a lower maturation period. Respondents who mixed several climbing bean varieties could smooth harvest and consumption, and did not dislike a longer maturation period. However, our results indicate that maturation period is less important relative to other crop characteristics.

Despite significant interaction terms, not all preference heterogeneity is explained in our model. Even after analysing the respondents of the three food insecurity categories separately, some of the heterogeneity remains unexplained. In the full sample, there remains some unexplained random variation for the opt-out option, for yield without mineral fertilizer application, for increased soil fertility and for seed price (with and without access to input credit). This means that respondents have varying 
Table 4. Parameter estimates of the mixed logit (MXL) models for the full sample and three subsamples of food insecurity categories.

\begin{tabular}{|c|c|c|c|c|}
\hline & $\begin{array}{c}\text { MXL } \\
\text { interacted }\end{array}$ & $\begin{array}{l}\text { Least food- } \\
\text { insecure } I^{\mathrm{a}}\end{array}$ & $\begin{array}{l}\text { Moderately food- } \\
\text { insecure } \mathrm{II}^{\mathrm{a}}\end{array}$ & $\begin{array}{l}\text { Severely food- } \\
\text { insecure III }\end{array}$ \\
\hline \multicolumn{5}{|l|}{ Mean } \\
\hline ASC & $\begin{array}{c}-7.5275^{* *} \\
(3.3576)\end{array}$ & $\begin{array}{l}-0.1048 \\
(0.7412)\end{array}$ & $\begin{array}{c}-3.1403^{* * *} \\
(1.0228)\end{array}$ & $\begin{array}{c}-20.5686 \\
(7467.452)\end{array}$ \\
\hline Seed price ${ }^{b}$ & $\begin{array}{l}-0.5612^{* *} \\
(0.2738)\end{array}$ & $\begin{array}{c}0.5933 \\
(0.8551)\end{array}$ & $\begin{array}{l}-0.3549 \\
(0.3960)\end{array}$ & $\begin{array}{l}-1.3338^{* *} \\
(0.5251)\end{array}$ \\
\hline Yield without fertilizer & $\begin{array}{l}0.2831^{* * *} \\
(0.0288)\end{array}$ & $\begin{array}{l}0.2958^{* * *} \\
(0.0741)\end{array}$ & $\begin{array}{l}0.2481^{* * *} \\
(0.0352)\end{array}$ & $\begin{array}{l}0.3424^{* * *} \\
(0.0561)\end{array}$ \\
\hline Yield with fertilizer & $\begin{array}{l}0.1383^{* * *} \\
(0.0177)\end{array}$ & $\begin{array}{l}0.1470^{* * *} \\
(0.0356)\end{array}$ & $\begin{array}{l}0.1423^{* * *} \\
(0.0264)\end{array}$ & $\begin{array}{l}0.1335^{* * *} \\
(0.0297)\end{array}$ \\
\hline Soil fertility increase & $\begin{array}{l}0.1329^{* * *} \\
(0.0116)\end{array}$ & $\begin{array}{l}0.1496^{* * *} \\
(0.0318)\end{array}$ & $\begin{array}{l}0.1274^{* * *} \\
(0.0139)\end{array}$ & $\begin{array}{l}0.1342^{* * *} \\
(0.0204)\end{array}$ \\
\hline Maturation period & $\begin{array}{l}-0.0042 \\
(0.0042)\end{array}$ & $\begin{array}{l}-0.0232^{*} \\
(0.0128)\end{array}$ & $\begin{array}{c}0.0035 \\
(0.0057)\end{array}$ & $\begin{array}{l}-0.0101 \\
(0.0072)\end{array}$ \\
\hline Seed price ${ }^{*}$ Input credit & $\begin{array}{c}0.9165 \\
(0.6386)\end{array}$ & $\begin{array}{c}0.9014 \\
(1.6807)\end{array}$ & $\begin{array}{c}0.2809 \\
(0.8040)\end{array}$ & $\begin{array}{l}1.7418^{* *} \\
(0.8730)\end{array}$ \\
\hline Yield with fertilizer * Fertilizer & $\begin{array}{c}0.0345^{*} \\
(0.0180)\end{array}$ & $\begin{array}{c}0.0436 \\
(0.0385)\end{array}$ & $\begin{array}{c}0.0096 \\
(0.0270)\end{array}$ & $\begin{array}{l}0.0663^{* *} \\
(0.0309)\end{array}$ \\
\hline Maturation period * Mix climbing beans & $\begin{array}{c}0.0127 \\
(0.0086)\end{array}$ & $\begin{array}{l}0.0652^{* *} \\
(0.0265)\end{array}$ & $\begin{array}{c}0.0055 \\
(0.0139)\end{array}$ & $\begin{array}{c}0.0112 \\
(0.0130)\end{array}$ \\
\hline \multicolumn{5}{|l|}{ Standard deviation } \\
\hline Seed price & $1.0585^{*}$ & $2.1797^{* *}$ & $1.5466^{* * *}$ & $1.4923^{*}$ \\
\hline Yield without fertilizer & $0.1165^{* *}$ & 0.0284 & 0.0000 & $0.2103^{* * *}$ \\
\hline Yield with fertilizer & $0.0510^{* * *}$ & 0.0001 & $0.0579^{* * *}$ & $0.0457^{* *}$ \\
\hline Soil fertility increase & $0.0436^{* * *}$ & $0.0822^{* * *}$ & -0.0012 & $0.0603^{* * *}$ \\
\hline Maturation period & 0.0006 & & & \\
\hline Seed price * Input credit & $2.7378^{* * *}$ & & & \\
\hline Yield with fertilizer * Fertilizer & 0.0077 & & & \\
\hline Maturation period ${ }^{*}$ Mix & 0.0004 & & & \\
\hline chi2 & 26.95 & 5.70 & 10.02 & 10.09 \\
\hline$p($ chi2) & 0.0014 & 0.22 & 0.04 & 0.04 \\
\hline$l l$ & -705.23 & -103.26 & -331.19 & -57.56 \\
\hline aic & $1,446.46$ & 232.52 & 688.39 & 541.11 \\
\hline bic & $1,565.15$ & 293.58 & 763.73 & 614.92 \\
\hline$N$ & 5,400 & 810 & 2,430 & 2,160 \\
\hline
\end{tabular}

Notes: a Household food insecurity categories determined according to FANTA method (Coates et al, 2007). Group I consists of foodsecure and mildly food-insecure farmers. 'beed price is expressed in 1,000 FBu. Standard errors are in parentheses. Coefficients are significant at ${ }^{* * *} p<0.01 ;{ }^{* *} p<0.05 ;{ }^{*} p<0.10$.

preferences for these attributes. In the subsamples, we found unexplained heterogeneity for the seed price, yield with or without mineral fertilizer and increased soil fertility. The signs of the coefficients for yield increase with mineral fertilizer, as well as for increased soil fertility, are unambiguously positive. This indicates that respondents have positive preferences for these attributes, but some respondents have stronger preferences than others (Table 4 ).

For the seed price coefficients, the standard deviations are relatively large. In the full sample, the majority of farmers who did not receive input credit (over $90 \%$ ), and a minority of farmers who received input credit (42\%), preferred a lower seed price, while other farmers seemed to have no preferences for this attribute, or even preferred a higher seed price (for a small share of the farmers in the sample $(28 \%)$, we found a positive parameter for the seed price). Other studies (for example, Birol et al, 2011) also found insignificant price effects. Possible explanations include the possibility that respondents do not care about the attribute, too small a range in the attribute levels to capture significant effects, correlation between seed price and seed quality and/or heterogeneous preferences. Since our research was based within an extremely poor region, and since the price range was based on actual market information, it is unlikely that farmers do not care about the seed price. One possible explanation is that some farmers multiply seeds and sell them, such that a higher seed price would benefit them. Seed-saving is a common practice in the area and farmers regularly sell seeds to other farmers in case of surpluses. Another possible explanation is that seed with a higher price is believed to yield higher-quality produce that can be sold at a higher price.

\section{Conclusions}

We used a choice experiment to analyse farmers' preferences for improved climbing bean varieties in Burundi, and found that farmers had a strong preference for climbing bean varieties that resulted in higher yields and improved soil fertility, while the maturation period and the responsiveness to fertilizer were less important. This implies that, within certain limits, breeding efforts do not 
need to focus on the length of the growing period, but rather could focus on varieties that possibly take a bit longer to mature, but also produce more biomass, and can therefore be more beneficial for soil fertility. In addition, we found that the seed price mattered, but only for the most food-insecure farmers. This implies that there is scope for introducing agricultural technologies in extremely poor countries. Our study confirms that choice experiments can provide useful ex ante insights about the potential of new agricultural technologies. Choice experiments can inform agricultural research and extension programmes before they are implemented or upscaled. If such programmes can better take into account the preferences of local farmers, the adoption of new technologies may be accelerated.

\section{Acknowledgments}

We gratefully acknowledge the support of the CIALCA project staff for the fieldwork in Burundi. We thank Lotte Willems for guiding the survey team. Special thanks to Pieter Pypers and Emily Ouma for extensive discussions on the choice of experiment design, and we thank workshop participants in Leuven, Ghent and Nairobi for their valuable feedback. The corresponding author is grateful for the research grant provided by FWO Vlaanderen.

\section{Notes}

1 Each commune consists of 'collines' and each colline contains different 'sous-collines'. Sous-collines can also be called villages.

2 Choice probabilities in mixed logit models must be numerically estimated. A large number of draws is needed to assure low simulation error in the estimated parameters. Halton sequences are commonly used in choice experiments to generate 'intelligent' draws from a distribution (Hensher et al, 2005).

\section{References}

Beekman, G., and Bulte, E.H. (2012), 'Social norms, tenure security and soil conservation: evidence from Burundi', Agricultural Systems, Vol 108, pp 50-63.

Bennett, J., and Birol, E. (2010), Choice Experiments in Developing Countries. Implementation, Challenges and Policy Implications, Edward Elgar Publishing, Northampton, MA.

Birol, E., Asare-Marfo, D., Karandikar, B., and Roy, D.A. (2011), Latent Class Approach to Investigating Farmer Demand for Biofortified Staple Food Crops in Developing Countries: The Case of
High-Iron Pearl Millet in Maharashtra, HarvestPlus Working Paper No 7, IFPRI, Washington, DC.

Checa, O., Ceballos, H., and Blair, M.W. (2006), 'Generation means analysis of climbing ability in common bean (Phaseolus vulgaris L.)', Journal of Heredity, Vol 97, No 5, pp 456-465.

Coates, J., Swindale, A., and Bilinsky, P. (2007), Household Food Insecurity Access Scale (HFIAS) for Measurement of Food Access: Indicator Guide (v. 3), Food and Nutrition Technical Assistance Project, Academy for Educational Development, Washington, DC.

Filmer, D., and Pritchett, L.H. (2001), 'Estimating wealth effects without expenditure data - or tears: an application to educational enrollments in states of India', Demography, Vol 38, No 1, pp 115-132.

Graham, P.H., and Rosas, J.C. (1977), 'Growth and development of indeterminate bush and climbing cultivars of Phaseolus vulgaris inoculated with Rhizobium', Journal of Agricultural Science, Vol 88, pp 503-508.

Greene, W.H. (2008), Econometric Analysis, 6 ed, Pearson Education, Upper Saddle River, NJ.

Hensher, D.A., and Greene, W.H. (2003), 'The mixed logit model: the state of practice', Transportation, Vol 30, pp 133-176.

Hensher, D.A., Rose, J.M., and Greene, W.H. (2005), Applied Choice Analysis. A Primer, Cambridge University Press, Cambridge.

Hoyos, D. (2010), 'The state of the art of environmental valuation with discrete choice experiments', Ecological Economics, Vol 69, pp 1595-1603.

Irz, X., Lin, L., Thirtle, C., and Wiggins, S. (2001), 'Agricultural productivity growth and poverty alleviation', Development Policy Review, Vol 19, No 4, pp 449-466.

Lunze, L., and Ngongo, M. (2011), 'Potential nitrogen contribution of climbing bean to subsequent maize crop in rotation in South Kivu Province of Democratic Republic of Congo', in Bationo, A., Waswa, B., Okeyo, J.M., Maina, F., and Kihara, J.M., eds, Innovations as Key to the Green Revolution in Africa, Springer, New York, pp 678-681.

McFadden, D., and Train, K. (2000), 'Mixed MNL models for discrete responses', Journal of Applied Econometrics, Vol 15, No 5, pp 447-470.

Pypers, P., Sanginga, J.-M., Bishikwabo, K., Walangululu, M., and Vanlauwe, B. (2011), 'Increased productivity through integrated soil fertility management in cassava-legume intercropping systems in the highlands of Sud-Kivu, DR Congo', Field Crops Research, Vol 120, No 1, pp 76-85.

Rousseau S., and Vranken, L. (2013), 'Green market expansion by reducing information asymmetries: evidence for labeled organic food products', Food Policy, Vol 40, pp 31-43.

Vanlauwe, B., Bationo, A., Chianu, J., Giller, K.E., Merckx, R., Mokwunye, U., Ohiokpehai, O., Pypers, P., Tabo, R., Shepherd, K.D., Smaling, E.M.A., Woomer, P.L., and Sanginga, N. (2010), 'Integrated soil fertility management: operational definition and consequences for implementation and dissemination', Outlook on Agriculture, Vol 39, No 1, pp 17-24. 